\title{
EFFECT OF STORAGE ON THE VOLATILE OIL CONTENT OF CLOVE BUDS (Syzygium aromaticum)
}

(Received: 7.4.2014)

\author{
By \\ J. Z. Altamimi and E. A. Alshehri \\ Department of Nutrition and Food Sciences, Princess Norah Bint AbdulRahman University, \\ Riyadh, Kingdom of Saudi Arabia
}

\begin{abstract}
This study has sought to know the effect of conventional storage of dried clove buds (Syzigium aromaticum) on their volatile oil content. Volatile oil was extracted from the three differently stored samples using the steam distillation method. The volatile oil content was estimated and the chemical constituents of the volatile oil were fractionated and identified in accordance with AOCA method by using Gas Chromatography/ Mass spectrometry technique (GC/MS). The findings indicated that storage for less than two months caused very slight changes concerning the volatile oil content and the percentages of its active constituents such as eugenol, eugenyl acetate and $\beta$-caryophyllene. However, these changes, were not statistically significant.
\end{abstract}

Key words: storage, Syzygium aromaticum, volatile oils.

\section{INTRODUCTION}

Spices and herbs were strongly present early in history. They were used in cooking for their distinctive flavor and their medinical and curative properties. Trading in spices was one of the most active and important commercial activities since the dawn of history. Most spices grow in Asia because of its tropical climate nature. Spices are known for their volatile oils and oily resins that account for their distinctive flavor and medicinal properties (Prabuseenivasan et al., 2006).

Volatile oils are unstable oils, ethereal oils, aetherolea or a mixture of the above compounds. They are produced naturally in plants. The volatile oil can be extracted using various methods, the most important of which is the mixing of the plant that contains the oil with water, or using dry or steam distillation (Husnu et al., 2007). These may be of a simple chemical structure such as clove (Syzigium aromaticum), coriander and vanilla or they may have a complex structure such as nutmeg or laurel (Politeo et al., 2007).

Syzigium aromaticum is one of the spices that are rich in volatile oils and acts as natural antioxidants. Musenga et al. (2006) mentioned that the essential oil of clove buds contains eugenol, eugenyl acetate, vanillin, Bcaryophyllene and crategolic acid. Wenqiang et al. (2007) indicated that the main constituent of clove (Syzigium aromaticum) buds oil is eugenol, which amounts to $58.77 \%$ of the total oil when extracted at a high percentage.

Alma et al. (2007) confirmed that the oil extracted from dried clove buds contains eugenol $(49-87 \%,) \quad \beta$-caryophyllene $(4-21 \%$, eugenyl acetate $(0.5-21 \%)$ and a slight percentage of $\alpha$-humulene.

These volatile oils are highly beneficial to health. However, they are quickly oxidized by heat, light and air (Djilani and Dicko, 2012). Hence, preservation of these properties requires special handling for storing and grinding spices. Al Shihri and Al-Tameemi (2012) found that most Saudi families grind Syzigium aromaticum and keep it in containers for use when required.

Thus, the objective of this study was to determine the effect of storage by two different methods; on Syzygium aromaticum spice in terms of its content and components of the volatile oil.

\section{MATERIALS AND METHODS}

Dried Clove (Syzigium aromaticum) buds were purchased from the local markets in Riyadh and samples were prepared as follows:

Sample A: representing the control. A sample of dried clove buds was finely ground immediately upon purchase and analyzed in the laboratory. 
Sample B: a sample of whole dried clove buds was stored in glass jars with narrow neck closed tightly for one month at room temperature $\left(20-23^{\circ} \mathrm{C}\right)$, then finely ground and analyzed immediately.

Sample C: a sample of whole dried clove buds was stored in glass jars with narrow neck closed tightly for one month at room temperature $\left(20-23^{\circ} \mathrm{C}\right)$, finely ground and stored in glass jars for an additional month at room temperature before being analyzed.

The research adopted the experimental analytical method (Obaidat et al., 2000). Steam distillation was used for estimating the oil quantities in the samples. Gas Chromatography / Mass Spectometry (GC/MS, GCMS, QP-2010 Auto Injector-AOC-5000, Vacuum Pump, Column Specification: Rtx.5MS (Crossbond:5\% diphenyl L 95\% dimethyl polysiloxane), 30 meter, $0.25 \mathrm{~mm}$ ID, $0.25 \mathrm{um}$ df, cat \# 12623 Serial \# 882023, Max. Programmable Temp. $350^{\circ} \mathrm{C}$. Minimal bleed at $330{ }^{\circ} \mathrm{C}$ ) was used for quantitative and qualitative estimation of volatile oils in the samples in accordance with the Association of Official Analytical Chemists, method (AOAC, 2000).

The results were summarized in tables and diagrams for easy interpretation. SPSS, V15 was used for statistical analysis of the data. One-way ANOVA was used for determining the statistical differences between the three samples (Steel and Torri 1980).

\section{RESULTS AND DISCUSSION}

Table (1) and Fig. (1) show that the quantity of the oil extracted from recently purchased and ground clove; the control was $15.34 \mathrm{gm} / 100 \mathrm{gm}$ of the powder, whereas in the sample B which represents the whole clove buds stored complete for a whole month at room temperature and then ground, the extracted oil was $15.52 \mathrm{gm} / 100 \mathrm{gm}$ and in the whole cloves stored at room temperature $\left(20-23{ }^{\circ} \mathrm{C}\right)$ then ground and stored for an additional month at room temperature, representing sample $\mathrm{C}$, the extracted oil quantity was $13.67 \mathrm{gm} / 100 \mathrm{gm}$.

Silano and Anton (2001) stated that the quantity of oil in clove buds amounted to $20 \%$ or more of its weight. On the other hand, Peter (2004) stated that ground or complete clove buds contain about $15-20 \%$ of their weight as volatile oil. The slight differences in the findings are due to various reasons, key among which are the method used for extracting the oil, precision of the used equipment and the type of solvent (Wenqiang et al., 2007). The findings also indicate that storage affects clove total content of oil. This is remarkable when storage is performed after grinding. The difference in this study is, however, not statistically significant because of the short storage period. This is confirmed by Peter (2004) who mentioned that storage of clove buds leads to losing oil through evaporation. The loss ratio depends on several factors most important of which are physical condition, moisture content and the temperature and moisture of the storage location. The total oil percentage in the buds is slightly reduced after storage for a period of one month.

Table (2) and Fig. (2) show the quantity and type of oils present in the studied samples. It is clear that the main constituent of clove buds oil is eugenol, followed by eugenyl acetate and $\beta$ caryophyllene. Srivastava et al. (2005) revealed that when oil is extracted from Madagascar clove buds by steam distillation the oil will contain eugenol at $82.6 \%$ of the total oil with $6 \%$ eugenyl acetate, $7.2 \%$ of $\beta$-caryophyllene, slight percentages of MethlySalisylate estimated at $0.05 \%$ and $1.5 \%$ Alpha humulene.

Alma et al. (2007) extracted oil from Turkish clove buds using steam distillation for three hours. The oil content in the extracted oil was analyzed. They found that the oil extracted from Turkish clove buds contained 18 constituents with eugenol constituting the highest percentage of these constituents at about $87 \%$ of the total oil, followed by engenol acetate at about $8.01 \%$

Table (1): Effect of grinding and storage on the yield of the clove buds volatile oil (on dry wt. gm/100gm), mean \pm SD.

\begin{tabular}{|c|c|c|c|}
\hline Samples & Sample A (Control) & Sample B & Sample C \\
\hline $\begin{array}{c}\text { Quantity of the } \\
\text { extracted oil }\end{array}$ & $15.34 \pm 0.99$ & $15.52 \pm 0.70$ & $13.67 \pm 0.72$ \\
\hline
\end{tabular}

Control Sample A: clove recently purchased, ground and oil immediately extracted from it.

B: Whole Clove buds were stored for one month at room temperature $\left(20-23^{\circ} \mathrm{C}\right)$, then ground and oil extracted.

$\mathrm{C}$ : Whole Clove buds were stored for one month at room temperature $\left(20-23^{\circ} \mathrm{C}\right)$, then ground and stored for an additional month at room temperature. 


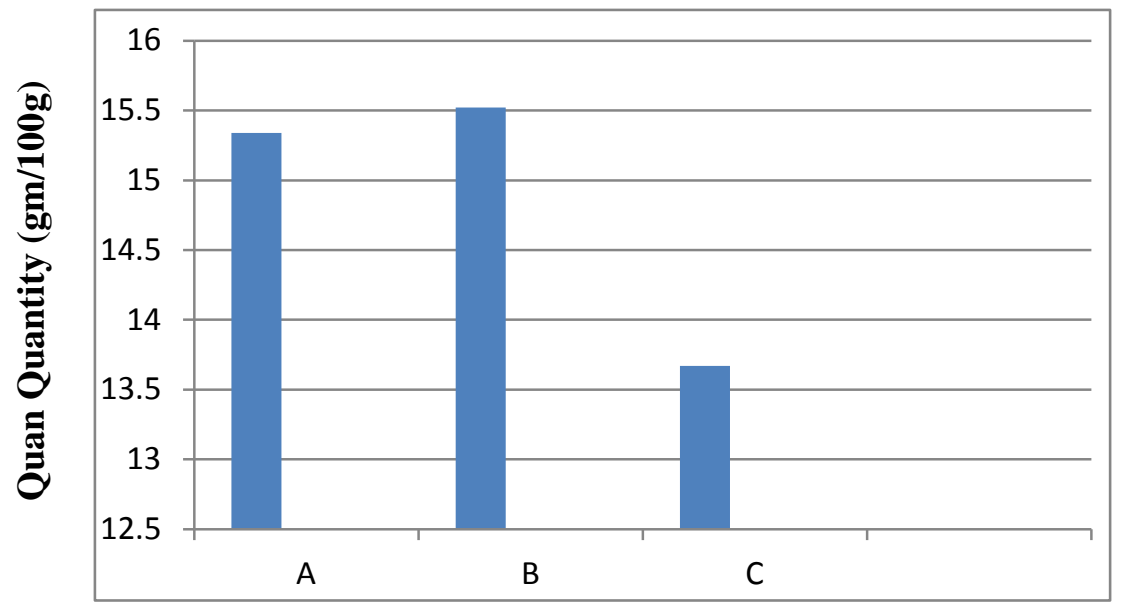

Tested sample

Fig. (1): Quantity of the volatile oil extracted from the three samples (gm/100g).

Table (2): Effect of grinding and storage on the chemical constituents of the clove buds volatile oil by using GC/MS technique.

\begin{tabular}{|c|c|c|c|c|c|c|}
\hline \multirow{2}{*}{ Chemical constituents } & \multicolumn{2}{|c|}{ Control Sample A } & \multicolumn{2}{|l|}{ Sample B } & \multicolumn{2}{|l|}{ Sample C } \\
\hline & gm & $\%$ & gm & $\%$ & gm & $\%$ \\
\hline Eugenol & $0.86 \pm 10.16$ & 66.24 & $0.69 \pm 10.57$ & 68.11 & $0.71 \pm 8.98$ & 65.68 \\
\hline Eugenyl Acetate & $0.12 \pm 2.54$ & 16.56 & $0.00 \pm 2.76$ & 17.77 & $0.01 \pm 2.67$ & 19.44 \\
\hline$\beta$-Caryophyllene & $0.01 \pm 2.18$ & 14.21 & $0.01 \pm 1.75$ & 11.26 & $0.05 \pm 1.67$ & 12.23 \\
\hline$\alpha$-Caryophyllene & $0.00 \pm 0.25$ & 1.61 & $0.00 \pm 0.20$ & 1.22 & $0.00 \pm 0.18$ & 1.35 \\
\hline Methyl Salisylate & $0.00 \pm 0.01$ & 0.07 & $0.00 \pm 0.02$ & 0.11 & $0.00 \pm 0.04$ & 0.31 \\
\hline Caryophyllene Oxide & $0.00 \pm 0.06$ & 0.38 & $0.00 \pm 0.08$ & 0.50 & $0.00 \pm 0.06$ & 0.46 \\
\hline Copaene & $0.00 \pm 0.05$ & 0.3 & $0.00 \pm 0.03$ & 0.20 & $0.00 \pm 0.02$ & 0.17 \\
\hline Alpha-Farnesene & $0.00 \pm 0.04$ & 0.26 & $0.00 \pm 0.03$ & 0.20 & $0.00 \pm 0.01$ & 0.10 \\
\hline Cavicol & $0.00 \pm 0.02$ & 0.13 & $0.00 \pm 0.02$ & 0.11 & $0.00 \pm 0.02$ & 0.12 \\
\hline a-Cubebene & $0.00 \pm 0.01$ & 0.09 & -- & --- & ---- & ---- \\
\hline Aromadendrene Oxide-(2) & $0.00 \pm 0.01$ & 0.07 & $0.00 \pm 0.02$ & 0.11 & $0.00 \pm 0.02$ & 0.11 \\
\hline Cadina-1(10),4—diene & $0.00 \pm 0.01$ & $\mathbf{0 . 0 7}$ & $0.00 \pm 0.01$ & 0.05 & Effects & 0.02 \\
\hline Germacrene D & Effects & 0.07 & Effects & 0.01 & --- & --- \\
\hline$\alpha$-Terpineol Acetate & --- & --- & $0.00 \pm 0.06$ & 0.35 & Effects & 0.01 \\
\hline Total & 15.34 & 100 & 15.52 & 100 & 13.67 & 100 \\
\hline
\end{tabular}

Control Sample A: clove recently purchased, ground and oil immediately extracted from it.

B: Whole Clove buds were stored for one month at room temperature $\left(20-23^{\circ} \mathrm{C}\right)$, then ground and oil extracted.

C: Whole Clove buds were stored for one month at room temperature $\left(20-23^{\circ} \mathrm{C}\right)$, then ground and stored for an additional month at room temperature. 


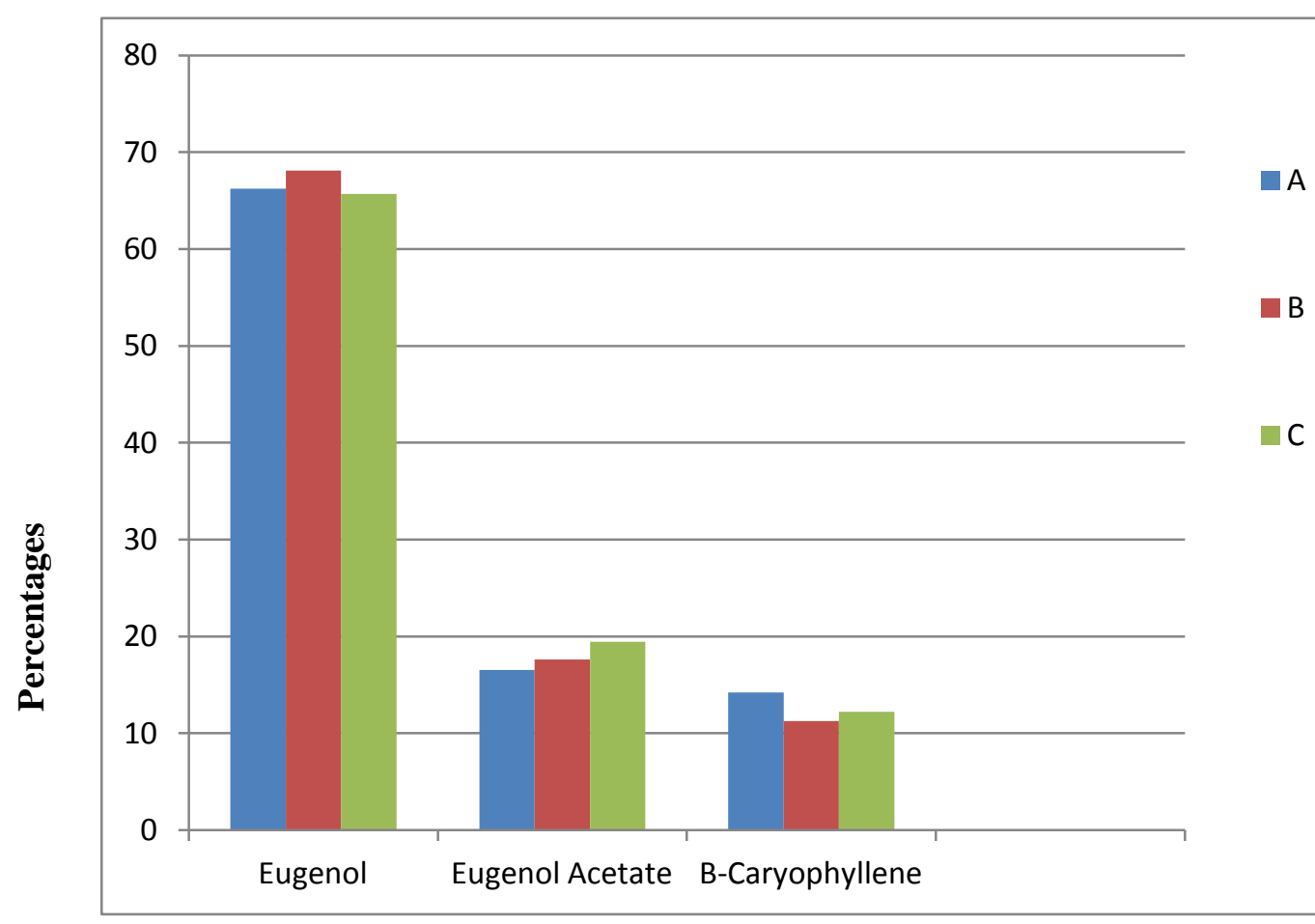

\section{Constituent}

Fig. (2): Percentages of the major constituents of the volatile oil in the three samples.

and then $\beta$-caryophyllene with a percentage of $3.56 \%$. The remaining constituents represented only a very small percentage of the total oil. Nassar et al. (2007), revealed that eugenol percentage in clove buds oil reached $71.56 \%$ and that eugenol acetate reached a percentage of $8.99 \%$ of the total oil. The difference in the findings of these studies is due to the different methods used for extracting the total oil form dry clove buds, the equipment used and its precision and the type of solvent (Wenqianq et al., 2007). "MMWD" (2008) attributed the variations in the percentages of the constituents of clove bud oil to several causes, key among which are plant hereditary strain, climate, type of soil, agricultural technologies, method of harvesting and the harvested part of the plant. Misharina and Samusenko, (2008) indicated that the quantity and kind of antioxidants in spices and herb essential oils depend on the method used for extracting these oils and the kinds of solutions used in the extraction process. Peter (2004) pointed out that the quantity of eugenol in the extracted oil depends on the time taken by distillation, with fast distillation yielding oil with a high percentage of eugenol. Table (2) shows that the percentages of volatile oil constituents varied very slightly without any significant differences because of the short storage period. But, the Table also shows that the eugenol percentages increased very slightly in sample B compared to control sample A. This may be due to the loss of moisture through evaporation during storage which has led to its concentration. In sample $\mathrm{C}$ the eugenol level decreased because of its grinding and storage. The level of Beta caryophyllene decreased in the two stored samples compared to the control sample.

Peter (2004) referred to the effect of storage and grinding on dried clove buds oil, stating that eugenol acetate decreased slightly after storage whereas eugenol increased. These changes usually take place after storage for six months if adequate storage conditions are taken into consideration. Grinding produces an oil with a low content of eugenol because of the loss of a quantity of volatile oil during grinding, hence distillation of ground clove buds is performed immediately after the grinding.

These findings indicate that despite the short period during which the dried clove buds were stored, slight statistically insignificant changes occurred in the quantity and constituents of the volatile oil. Thus, the study recommends conducting further research on the effect of storage on spices volatile oils, storing the materials for longer periods. 


\section{REFERENCES}

Alma M. H., Ertaz M., Nitz S. and Kollmannsberger H. (2007). Chemical comosition and content of essential oil from the bud of cultivated turkish clove (Syzygium aromaticum L). Bio. Resources, 2 (2): 265-269.

Al-Shihri E. and Al-Tamimi J. (2012). Evaluation of the pattern of the clove spice consumption by a sample of Saudi families and a sample of non-insulin dependent dietetics in the City of Riyadh, Pamphlet of the National Nutrition Institute of Egypt Arab Republic, Vol. 39, 202-232.

AOAC (2000). Official Methods of Analysis of the AOAC International. $17^{\text {th }}$ edition. Pub. By AOAC International Suite 500. Gaithersburg, Maryland, 20877-2417, USA.

Djilani A and Dicko A. (2012). The Therapeutic Benefits of Essential Oils, Nutrition, WellBeing and Health, Dr. Jaouad Bouayed (Ed.), ISBN: 978-953-51-0125-3, In Tech, Available

from:http://www.intechopen.com/books/nutr ition-well-being-and-health/the-therapeuticbenefits-of-essential-oils.

Husnu K., Baser C. and Demirci F. (2007). Chemistry of Essential oils. Flavours and Fragrances.pp 43-86.

MMWD (2008). Marin Municipal Water District. Vegetation Management Plan. Herbicide Risk Assessment. Clove Oil (Eugenol). Chapter 6:1-48.

Misharina T. A. and Samusenko A.L.(2008). Antioxidant properties of essential oils from lemon, grapefruit, coriander, clove, and their mixtures.

PrikladnayaBiokhimiyaiMikrobiologiya. 44 (4): 482-486.

Musenga A., Ferranti A., Saracino M. A., Fanali S and Raggi M. A. (2006). Simultaneous determination of aromatic and terpenic constituents of cloves by means of HPLC with diode array detection. J. Separation Sci., 29 (9): 1251 - 1258.

Nassar M. I., Gaara A. H., ELGhorab A. H., Farrag A. R. H., Shen H., Huq E. and Mabry T. J. (2007). Chemical constituents of clove (Syzygium aromaticum, Fam Myrtaceae) and their antioxidant a activity. Rev. Latinoamer. Quim. 35(5): 48-57.

Obaidat T., Ads A. and Abdul Haq K. (2000). Scientific Research; Its Concept, Tools, Methods, First Edition, Dar Osama for Publishing and Distribution. Riyadh. Saudi Arabia.

Peter K.V. (2004). Handbook of Herbs and Spices. Vol. 2.1 ${ }^{\text {st }}$ ED.CRC Press.,1-360.

Politeo O., Jukic M \& Milos M. (2007). Chemical composition and antioxidant capacity of free volatile aglycones from basil (Ocimum basilicum L.) compared with its essential oil. Food Chem.101 :379-385.

Prabuseenivasan S., Jayakumar M. and Ignacimuthu M. (2006). BMC Complementary and Alternative Medicine In vitro antibacterial activity of some plant essential oils. BioMed Central,_6 (39):1-8

Silano V. and Anton R. (2001). Plants in Cosmetics.Volume II. Council of Europe Publishing, Strasbourg.

Srivastava A. K., Srivastava S. K., and Syamsundar K.V. (2005). Bud and leaf essential oil composition of Syzygium aromaticum from India and Madagascar. Flavour and Fragrance, J. 20 (1): 51.

Steel R.G. D. and Torri J.H. (1980). Principles and Procedures of Statistics. $2{ }^{\text {nd }}$ Ed., Mc Graw Hill.Inc., New Yourk. USA.

Wenqiang G., Shufen L., RuixiangY., Shaokun T. and Can Q. (2007). Comparison of essential oils of clove buds extracted with supercritical carbon dioxide and other three traditional extraction methods. Food Chem. 101 (4):1558-1564.

$$
\begin{aligned}
& \text { تأثير التخزين على محتوى براعم القرنفل من الزيوت الطيارة }
\end{aligned}
$$

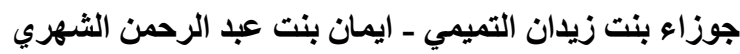

$$
\begin{aligned}
& \text { قسم التغذية وعلوم الأطعمة - جامعة الأميرة نورة بنت عبد الرحمن - الرياض ـ المملكة العربية السعودية }
\end{aligned}
$$$$
\text { هدفت هذه الدراسة الى التعرف علي تأثير التخزين بالطرق التقليدية على محتوى براعم القرنفل المجففة من الزيت الطيار. حيث الزيث }
$$

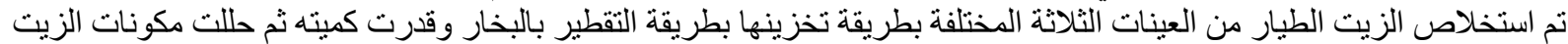

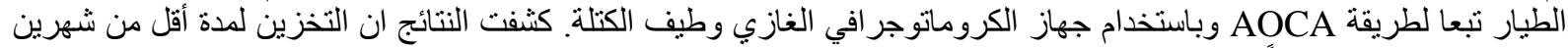

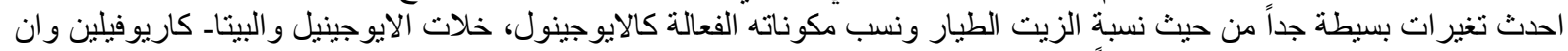$$
\text { كانت هذه التغير ات غير معنوية احصائياً. }
$$ 